\title{
ANIMAÇÃO COMO FERRAMENTA NO PROCESSO DE MEDIAÇÃO DO ENSINO E APRENDIZAGEM DE ALUNOS DA MODALIDADE DE ENSINO A DISTÂNCIA
}

\author{
CURITIBA/PR JULHO/2018
}

\author{
André Luiz Pinto dos Santos - UNINTER - andreluizretratista@gmail.com \\ Rodrigo Otávio dos Santos - UNINTER - rodrigoscama@gmail.com \\ Tipo: Investigação Científica (IC) \\ Natureza: Relatório Final de Pesquisa \\ Categoria: Métodos e Tecnologias \\ Setor Educacional: EDUCAÇÃO SUPERIOR
}

\begin{abstract}
RESUMO
No presente trabalho pretende-se responder a seguinte problemática: a linguagem da animação pode ser utilizada como ferramenta no processo de mediação da aprendizagem de alunos da modalidade de ensino a distância? Para responder esta inquietação procurou-se através de uma pesquisa bibliográfica elaborar primeiramente um breve panorama histórico do processo de animação, depois em segundo momento conhecer o perfil do aluno que estuda a partir da modalidade à distância e por fim compreender o processo de mediação a partir de Vygotsky. Questiona-se a partir de dados averiguados nesta pesquisa, por que as instituições pouco utilizam a animação em seus cursos de graduação, como ferramenta de mediação. Acredita-se que a animação pode contribuir para com a aquisição de informação pelo o aluno e que, portanto, este pode vir a refletir sobre o conteúdo exposto gerando conhecimento.
\end{abstract}

Palavras-chave: Animação; Ensino a Distância; Mediação 


\section{Introdução}

Existem muitas pesquisas sobre mediação a partir da ótica de Vygotsky. Muitas delas no campo da psicologia e da educação. Constatou-se também que existem muitas pesquisas sobre o perfil do aluno na modalidade à distância. E, ainda, existem muitos trabalhos referentes ao processo de animação. No entanto, quando a problemática inclina-se para o processo de mediação desenvolvido na modalidade de ensino a distância e em especial quando se averigua a linguagem da animação como ferramenta de mediação no processo de ensino e aprendizagem, vê-se que existe uma carência de pesquisas. Outro ponto observado é que se alega a necessidade de um aluno autônomo no $\mathrm{EaD}$, porém, é importante lembrarmos que a tutoria tem um papel fundante na elaboração de materiais que facilitem o processo de aprendizagem pelo aluno. Diante deste contexto houve a necessidade de trazer para o âmbito do discurso cientifico esta problemática. Neste artigo, portanto, se buscará averiguar as aproximações que a linguagem da animação pode ter a partir dos estudos de Vygotsky sobre mediação, e então discutir a ideia do uso da linguagem da animação como ferramenta de mediação no processo de ensino e aprendizagem no ensino a distância.

\section{A Animação}

Quando se pensa em animação, logo vem à mente a ideia de desenho, e consequentemente, desenhos que se movam. De acordo com Lucena Júnior (2011), a palavra veio do verbo latino animare ou "dar vida a". A partir da definição de Lucerna sobre animação, pode-se deduzir que um dado objeto ou situação podem ser compreendidos no tempo e no espaço, ou seja, visto quadro a quadro e de maneira sequencial, criando efeito de ilusionismo. De acordo com Rudolf Arnheim (2005) o movimento é a atração visual mais intensa da visão. Para Magalhães (2015, p.11) a "Animação é a arte de conferir a ilusão de vida, através do movimento, a objetos inanimados". A ideia de animação não é nova. No século XVIII, Pieter van Musschenbroek, ao girar um disco com imagens sequenciadas percebeu o efeito de movimento. Musschenbroek incrementa seu aparelho de animação ao colocar múltiplas luzes a partir de imagens sincronizadas e posteriormente mostradas para o público, segundo Lucena Junior (2011). Os primeiros aparelhos que possibilitaram a animação surgiram entre os anos de 1828 e 1832 pelos cientistas Joseph Plateau e Simon von Stampfer. Plateau foi o responsável pela criação do fenaquistoscópio. Segundo Lucena Junior (2011) este aparelho consistia em um disco com pequenas aberturas que intercalavam imagens sequenciadas. Este disco era preso por um eixo que permitia uma rotação e o eixo era preso em um cabo que permitia ao observador segurar o aparelho enquanto havia de forma simultânea o giro do disco. Ao colocar o aparelho frontal a um 
espelho e olhar pelas frestas o observador via a sequência de imagens se sobrepor criando a ilusão de movimento.

Ainda segundo Lucena Junior (2011) em 1868 surgiria o que hoje chamamos de flipbook, ou como era chamado na época kineograf que consiste em um bloco de papel onde em cada uma de suas folhas há um objeto, personagem ou situação ligeiramente modificado. Quando as páginas deste bloco de papel são viradas rapidamente criava-se a sensação de movimento. Com Thomas Edison e William Dickson, em 1891, de acordo com Barbosa (2007) surge o kinetoscópio. Uma máquina que permitia que apenas uma pessoa olhasse a passagem rápida de uma película de filme perfurada. Esta máquina possuía correntes que faziam a transição das imagens. Posteriormente, em 1895, os irmãos Lumière aperfeiçoaram a máquina de Edison e criaram o cinematógrafo. Verificase, portanto, o resultado ilusório de movimento do cinema faz parte de tentativas idealizadas para a obtenção da animação, visto que, a animação foi em relação ao cinema, como relata Magalhães (2015) a primeira a se tornar popular. Esta popularidade, da animação enquanto tecnologia, por volta da primeira década do século XX já não era uma novidade segundo Lucena Junior (2011).

De acordo com Fusari (2002) em 1908, Émile Cohl produz o "Fantasmagorie", que é considerado o primeiro desenho animado a partir do desenho quadro a quadro fotografado. A técnica do acetato, que consiste em realizar cada fase de um desenho a partir de uma película de acetato. Este suporte é transparente, e nele, os personagens, desenhados, eram pintados com tinta acrílica e sobrepostos ao cenário, Com está técnica, o fundo poderia ficar estático, enquanto os personagens se movimentavam. De acordo Lucena Junior (2011) revoluciona a forma manual de se fazer animação, pois separava o personagem de seu cenário. Fossatti (2009) afirma que simultaneamente Walt Disney revolucionava a linguagem da animação em seus estúdios, e a partir da animação "Os três porquinhos" passava-se a utilizar a técnica de stopmotion a partir de desenho 2D, ou seja, a animação feita a partir de desenhos ligeiramente diferentes quadro a quadro. Em o "O velho e o moinho" de 1937, Walt Disney passou a gravar com mais de uma câmera, o que the garantia profundidade entre os planos e mais realidade para as cenas animadas. Segundo Lucena Junior (2011) a partir de 1970 surgem às animações a partir de sistemas digitais. Era possível criar animações 2D, ou seja, em duas dimensões - altura e largura, como em 3D, ou seja, em três dimensões altura, largura e profundidade.

Como foi visto neste breve percurso histórico do processo de produção da animação, esta linguagem basicamente transforma imagens estáticas em imagens em movimento a partir de uma ilusão. Foi visto como as técnicas foram se aprimorando ao longo do 
tempo e o quanto a linguagem da animação sofreu transformações Hoje se utiliza da linguagem da animação para diversas ocasiões que vão daquelas criadas para entretenimento até mesmo as utilizadas para capacitar pessoas no mercado de trabalho. Todavia um dos objetivos desta pesquisa é verificar se a animação pode também funcionar como ferramenta de mediação no processo de aprendizagem de alunos da modalidade de ensino a distância.

\section{O aluno na modalidade à distância - EaD}

A modalidade de ensino a distância - EaD, de acordo com Carmem e Mattar (2007) é ilimitada, e proporciona a possibilidade de aprendizado a um grupo de alunos que não teria outra oportunidade se não estivesse nesta modalidade de ensino. Desta forma o EaD é democrático, possibilita pessoas com deficiência física ou mental ou mesmo pessoas que moram em lugares distantes de um centro de estudos discutirem, fomentarem a busca pelo conhecimento. Dados do CENSO EAD BR 2016, elaborado pela Associação Brasileira de Ensino a Distância - ABED, constatam um número maior do público feminino na composição das turmas EaD:

\footnotetext{
Com relação aos cursos regulamentados totalmente a distância, observamos que houve uma pequena maioria de público feminino. As mulheres se encontram em $54 \%$ nas instituições educacionais com fins lucrativos e $55 \%$ nas entidades sem fins lucrativos. Nas instituições públicas, a proporção do público feminino é ainda maior: 59\% nas instituições públicas federais, 64\% nas estaduais e 66\% nas municipais. (CENSO EAD BR, p.85, 2016)
}

Ainda segundo a pesquisa realizada pela ABED, o aluno do ensino a distância costuma ser de maior idade, onde a concentração está entre a faixa de 26 e 40 anos de idade. Este aluno possui uma maturidade já desenvolvida. Nota-se que o aluno desta faixa etária, na maioria das vezes, concilia estudo e trabalho como se vê no resultado do Censo EaD:

O Censo EAD.BR 2016 revelou que a maioria dos alunos de todas as modalidades de cursos estudam e trabalham, característica muito acentuada na EAD. Em 30\% das instituições, mais de $75 \%$ dos alunos de cursos regulamentados totalmente a distância estudam e trabalham. Já nos cursos semipresenciais e presenciais, esse percentual é de $24 \% \%$. (CENSO EAD BR,2016, p.89)

Desta forma, vê-se que o perfil do aluno possui um maior foco na autonomia, dado que se trata de um aluno que já está inserido no mercado de trabalho, e que possui além de suas obrigações e responsabilidades acadêmicas, muitas vezes, também, a de seu próprio sustento. O aluno $\mathrm{EaD}$ deve possuir, portanto, a competência de buscar de forma autônoma a resolução de problemas de seu aprendizado. O repertório dos alunos da modalidade à distância - EaD, tende a ser muito variado. Isso porque, as composições das turmas são heterogêneas, formada por pessoas de diferentes idades, 
regiões do país e culturas, o que acaba por dificultar a utilização de um padrão de ensino. A educação bancária de Paulo Freire, ou seja, aquela em que o professor dita um determinado conteúdo e espera que todos assimilem da mesma forma, como se fosse possível depositar conteúdos aos alunos, e ao cabo da aula todos teriam a mesma compreensão, não funciona na modalidade EaD. Desta forma, vê-se que o perfil do aluno possui um maior foco na autonomia, dado que se trata de um aluno que já está inserido no mercado de trabalho, e que possui além de suas obrigações e responsabilidades acadêmicas, muitas vezes, também, a de seu próprio sustento. $O$ aluno EaD deve possuir, portanto, a competência de buscar de forma autônoma a resolução de problemas de seu aprendizado.

Embora esta modalidade de ensino consiga atingir muitas pessoas, o número de evasões de cursos de graduação é grande, como é possível constatar em dados do último censo pela Associação de Ensino a Distância. Algumas das razões estão atreladas a fatores familiares, saúde, obrigações profissionais, e talvez pela dificuldade de adaptação ou compreensão do formato das aulas na modalidade à distância. No último Censo da ABED 2016, a maior parte das instituições que ofertam o ensino na modalidade à distância, alega desconhecer o motivo exato das evasões dos cursos. Uma hipótese poderia ser o excesso de informação textual, como fontes de informação, um indicativo, talvez possa ser extraído do último censo em 2016, mas, que acabam por não serem mediadas pelos tutores, de forma que fica a encargo do aluno compreender 0 que é dito nas linhas de livros e textos fornecidos pelos professores e coordenadores do curso. Talvez, para se gerar a autonomia esperada de um aluno, inserido na modalidade à distância, seja necessário que o ambiente virtual, ao qual ele está inserido, possua ferramentas adequadas que o capacite a realizar atividades por conta própria. Talvez antes de ler um livro com uma teoria densa, complexa, seja necessário intervir mediando o processo de transmissão de informações através de uma ferramenta mais direta e acessível a este aluno. Diante disso, vê se, que o ensino a distância tende a ser mais efetivo, e com maior chance de conclusão, para aquele aluno que já possui maior autonomia, na busca por informações. A autonomia passa a ser uma das chaves para a aprendizagem na modalidade EaD. Planejar, organizar o tempo e os objetivos, metas a serem alcançados são algumas características que se espera de um aluno na modalidade à distância, portanto.

Para Carmem e Mattar (2007), a princípio o aluno virtual possui mais autonomia do que aquele que assiste às aulas de forma presencial, afinal ele tem domínio sobre objetivos e percursos de seu aprendizado. Quanto maior a autonomia para obter a informação, menor será a necessidade de auxílio de um professor no processo de ensino e aprendizagem. Vale notar que o processo de mediação pode agregar neste processo 
pela busca de autonomia. Os autores explanam que mesmo sendo um público com idade mais avançada, ainda sim, o aluno da modalidade EaD não está totalmente preparado para uma aprendizagem independente. Na modalidade de ensino a distância, há um perfil de aluno esperado, assim como anteriormente fora descrito. Mas será que este perfil de fato é comprovado? Pouco se conhece do aluno que está do outro lado, a interação é baseada em um ser hipotético. Presume-se quem é o aluno. Mas será que esta autonomia tão esperada, não acaba por ser uma justificativa para a ausência do professor mediador? Será que ao pensar o processo de mediação do ensino, não se acaba por desenvolver também a autonomia do aluno?

Quando o ensino passa a ser mediado pela tecnologia, principalmente no caso do ensino a distância, exige-se do aluno a capacidade de resolver situações complexas que, muitas vezes, fogem de sua capacidade real de compreensão e execução. A maior parte dos cursos ofertados na modalidade a distância fornece, aos alunos, textos verbais como ferramenta de mediação. Muitos destes textos possuem um grau de complexidade que extrapola a capacidade real de compreensão do aluno. Será que não haveria outra forma de aproxima-lo do conteúdo mais complexo? Ao introduzir uma carga excessiva de textos verbais, aos quais os alunos não dominam não pode acarretar no desânimo e consequentemente na evasão de um curso de graduação na modalidade a distância? Será que ao invés de em um primeiro contato, o professor/tutor ofertar o texto verbal como ferramenta de mediação, não seria o caso de ofertar outra linguagem mais simples de compreensão? São muitas perguntas, mas cabe aqui apontar que o processo de autonomia na aprendizagem não depende exclusivamente do aluno. Metodologias, materiais didáticos e a forma com que é estruturado o sistema de ensino EaD é de extrema importância para que seja gerado a autonomia da aprendizagem pelo aluno.

\section{Introdução ao processo de medição segundo Vygotsky}

Lev Semyonovich Vygotsky nasceu na cidade de Orsha em 1896, mas desenvolveu boa parte de sua carreira profissional na cidade de Gomel, ambas as cidades pertencem a Bielorrússia. Vygotsky desenvolveu boa parte de sua produção acadêmica, na área da psicologia, na cidade Moscou na Rússia. Foi nessa cidade, em 1934, que Lev Semyonovich Vygotsky faleceu com 38 anos de idade. No Brasil, podemos citar algumas obras do psicólogo, como: Formação social da mente (1984), Pensamento e linguagem (1993) e A Construção do pensamento e da linguagem (2001). É possível relacionar a Teoria Sociocultural de Vygotsky em três eixos, a saber, a Zona de Desenvolvimento Proximal - ZDP, a Mediação Cognitiva e o Processo de internalização. No entanto, apenas a Zona de Desenvolvimento Proximal - ZDP será é de interesse para o foco do 
estudo aqui apresentado. De acordo com Vygotsky a Zona de Desenvolvimento Proximal

É a distância entre o nível de desenvolvimento real, que se costuma determinar através da solução independente de problemas, e o nível de desenvolvimento potencial, determinado através da solução de problemas sob a orientação de um adulto ou em colaboração com companheiros mais capazes. (Vygotsky, 1991, p.97)

Para que ocorra o processo de aprendizagem a partir do processo de mediação, se faz necessário um trabalho onde o aluno acabe por aprender com outro sujeito mais experiente, podendo ser seu professor ou um colega. Todavia a mediação se dá através do uso de instrumentos e signos. No processo de mediação, existe um ambiente de troca, onde um primeiro sujeito entra em contato com a informação mediada por um segundo sujeito. Desta forma o mediador procurará fornecer as condições necessárias para que o mediado internalize as informações e reflita sobre elas de forma a gerar o conhecimento. Ao se referir ao pensamento de Vygotsky, sobre mediação dialética, Quadros (2017) faz referência à relação individuo/sociedade onde alega ser um comportamento na natureza social, contrariando a ideia de que a relação estaria presente desde o nascimento do indivíduo. Ainda expõe que não se trata de pressões internas, ou seja, intrapessoais, mas, são fruto de um intercâmbio de vivências sociais e históricas. Trata-se de uma relação dialética do homem e seu meio sociocultural. Desta forma o sujeito tende a modificar o seu entorno e, com isso, acaba por se transformar. A experiência sociocultural é o meio pelo qual Vygotsky identificava os mecanismos do desenvolvimento dos processos psicológicos, ou seja, a formação da consciência.

Desta forma, as funções psicológicas superiores do homem, como é o caso da percepção, memória e pensamento, são desenvolvidas a partir do relacionamento entre o aspecto social e cultural dos indivíduos. Assim, para que o homem seja capaz de conhecer o mundo, ou mesmo, estabelecer novas relações significantes com o seu entorno há uma necessidade de relacionamento social e cultural com outros indivíduos. Para que ocorra o desenvolvimento das funções psicológicas superiores, se faz necessário que haja uma internalização de um fenômeno, por um sujeito, a partir da utilização de instrumentos de mediação. Trata-se de uma nova combinação cognitiva e intersubjetiva. Um dado externo altera um "pré-conhecimento" interno. Trata-se de um processo interpessoal para um processo intrapessoal. Desta forma, é possível compreender que, um dado fenômeno só poderá ser compreendido, a partir de uma dada representação dele feita. O fenômeno só é para o sujeito que o internaliza, depois de ter sido para outros sujeitos envolvidos na mediação, ou seja, o conhecer é um ato histórico, social, e não um fenômeno individual e natural. De acordo com Cavalcanti: 
que o homem entra em interação. Trata-se de uma operação fundamental para o processo de desenvolvimento de funções psicológicas superiores e consiste nas seguintes transformações: de uma atividade externa para uma atividade interna e de um processo interpessoal para um processo intrapessoal. (CAVALCANTI, 2005, p.188).

Para se aprender sobre um determinado objeto, por exemplo, uma colher. Aprende-se primeiro a escrever e a falar a palavra colher (processo de aquisição de linguagem), ou seja, aprende-se o seu significado, para só depois compreender funções mais complexas da colher, como, por exemplo, o fato de a colher servir de instrumento para um sujeito levar a sopa até a boca, ou seja, sua significação. Desta forma, a representação pode indicar um determinado fenômeno, como é o caso de a palavra "colher", como servir de equivalente mental para o sujeito. A apropriação cultural que a linguagem desenvolve na mediação, portanto, é algo a ser destacado. É importante notar que a linguagem é acaba por permear nosso conhecimento de diversas formas, todavia, não se pode esquecer que existem várias possibilidades de linguagem e, desta forma, podemos entender linguagem como: a linguagem escrita e falada, como bem descreve Vygotsky, mas não podemos deixar de fora a pintura, o desenho, a escultura, a gravura, a fotografia, a animação dentre tantas outras que aqui poderiam ser listadas. Para este trabalho interessa averiguar a importância da animação enquanto ferramenta de mediação, e acima de tudo, como ferramenta capaz de auxiliar alunos no processo de aprendizagem a partir da modalidade do ensino a distância.

\section{Conclusão/Considerações Finais}

Como foi visto anteriormente ao animar uma imagem, ou seja, ao criar a ilusão de movimento para uma imagem estática, cria-se também a expectativa pelo acontecimento, pelo o que o olho não viu, mas que o cérebro espera que aconteça. Desta forma, a animação atrai o observador. Não precisa ir longe, basto entrar em uma sala de cinema, para constar que o público de filmes animados é bem heterogêneo, ou seja, composto por adultos e crianças. A animação possui, portanto, fácil assimilação. Assim, primeiramente foi traçado um panorama histórico da linguagem da animação, com o objetivo de localizar as etapas do desenvolvimento dessa linguagem, desde seus primeiros ensaios como brinquedos de ilusão óptica até a chegada da computação. Com o panorama histórico traçado, acredita-se que haja uma elucidação, quanto ao fato de que a animação como ferramenta de mediação está em constante processo de adaptação, estruturações, ajustes, evoluções técnicas, mas, que o cerne, movimento, se mantém.

Posteriormente, foram pontuadas, algumas das características do ensino e do aluno matriculado no ensino de modalidade à distância - EaD. Ao longo desta pesquisa, procurou-se deixar claro que a autonomia é o que se espera de um aluno no EaD. 
Alguns dados foram obtidos, a partir do Censo 2016, sobre o ensino a distância, e que traçam um possível perfil do aluno do EaD. Este aluno é composto, por uma boa parcela de pessoas que trabalham e que precisam de estimulo para continuarem com seus objetivos de estudo. Acredita-se, portanto, que a animação pode contribuir como parte deste estímulo e para com a aquisição de informação por parte do aluno, de forma tal que, este pode vir a refletir sobre o conteúdo exposto gerando conhecimento. Se o que se espera de um aluno da modalidade de ensino a distância é a autonomia, entende-se que o ambiente virtual, ao qual ele está inserido deve conter ferramentas que $\mathrm{o}$ auxilie a sair de seu nível real de aprendizado e que o capacite a chegar a seu nível potencial de aprendizado. Para isso, a linguagem da animação, pode ser uma ferramenta no processo de mediação.

Para pensar este processo de mediação, ou seja, este elo entre tutoria do $\mathrm{EaD}$ e o aluno no seu local de estudo, buscou-se a partir da Teoria de Mediação de Vigotsky, achar subsidio teórico para os pontos principais aqui abordados. Acredita-se que a linguagem da animação pode funcionar como ferramenta no processo de mediação da informação, e consequentemente, no processo de retenção da informação pelo aluno, e transformação desta informação de maneira crítica em conhecimento. É fato a necessidade de se mediar o processo de aprendizagem na modalidade à distância, onde o tutor tem um papel fundante assim como os colegas de turma. $\mathrm{O}$ tutor deve mediar fóruns, responder tutorias, e, sobretudo, planejar o material ao qual o aluno terá acesso. É este o ponto principal aqui levantado. Será que a animação pode aproximar o aluno de informações mais complexa? Como anteriormente afirmado, acredita-se que sim, pode fazer com que o aluno atinja estágios de execução de tarefas em que antes não estava capacitado. Buscou-se, portanto, através dos estudos de Vygotsky sobre mediação averiguar a animação como ferramenta no processo de ensino e aprendizagem de alunos da modalidade de ensino a distância, todavia trata-se de um estudo incipiente, e que merece novos olhares. Contudo, espera-se que de alguma forma, esta pesquisa venha a contribuir com os estudos de outros pesquisadores na área da educação e tecnologia.

\section{Referências}

ARNHEIM, Rudolf. Arte e percepção Visual: uma psicologia da visão criadora. São Paulo: Pioneira Thomson Learnin, 2005

BARBOSA, Marinalva. História Cultural da Imprenssa: Brasil 1900-2000. Rio de Janeiro: Mauad X, 2007 
CARMEM, Maria, MATTAR, João. ABC da EaD. 1ํㅡㄹ edição. São Paulo: Pearson Prentice, 2007.

CAVALCANTI, Lana de Souza. Cotidiano, Mediação Pedagógica e Formação de Conceito: uma contribuição de Vygotsky ao ensino de geografia. Cedes, Campinas, vol.25 n.66, p.185-207 maio/ago. 2005.

CENSO EAD.BR: relatório analítico da aprendizagem a distância no Brasil 2016 [livro eletrônico]/[organização] ABED - Associação Brasileira de Educação a Distância; [traduzido por Maria Thereza Moss de Abreu]. Curitiba: InterSaberes, 2017.

FOSSATTI, Carolina Lanner. Cinema de animação: uma trajetória marcada por inovações. In: VII ENCONTRO NACIONAL DAS MÍDIAS, 2009, Fortaleza, p. 1-21.

FUSARI, Maria Felisminda de Rezende e. 0 educador e o desenho animado que a criança vê na televisão. São Paulo: Edições Loyola, 2002.

LUCENA JÚNIOR, Alberto. Arte da animação: técnica e estética através da história. 3. ed. São Paulo: Senac São Paulo, 2011.

LUKESI, Cipriano Carlos. Filosofia da Educação. São Paulo: Cortez, 2003.

OLIVEIRA, Marta Kohl de. Vygotsky: aprendizado e desenvolvimento um processo sócio-histórico. 5ª edição. São Paulo: Scipione, 2010.

MAGALHÃES, Marcos Cartilha. Anima Escola: técnicas de animação para professores e alunos / texto Marcos Magalhães; [organização Joana Milliet, Marcos Magalhães; ilustrações Marcos Magalhães, Victor Pacheco]. -- 2. ed. -- Rio de Janeiro: IDEIA Instituto de Desenvolvimento, Estudo e Integração pela Animação, 2015.

QUADROS, Emérico Arnaldo de. Psicologia e desenvolvimento humano. Petrópolis: Vozes, 2017.

VYGOTSKY, Lev Semyonovich. A formação social da mente. 4aㅡ Edição. São Paulo: Martins Fontes, 1991. 